\title{
Komposit Magnet Permanen Berbasis NdFeB -Epoxy Resin dan Karakterisasinya
}

\author{
Mulyadi $^{1, *}$, Djuhana ${ }^{1}$, dan Ramlan ${ }^{2}$ \\ ${ }^{1}$ Jurusan Teknik Mesin, Fakultas Teknik Universitas Pamulang, Tangerang Selatan \\ ${ }^{2}$ Jurusan Fisika FMIPA Universitas Sriwijaya, Palembang, Sumatera Selatan. \\ E-mail: *dosen01545@unpam.ac.id
}

Masuk : 28 Februari $2018 \quad$ Direvisi : 26 Maret $2018 \quad$ Disetujui : 18 Mei 2018

\begin{abstract}
Abstrak: Telah dibuat komposit magnet permanen NdFeB dengan polimer epoksi resin (ER). Serbuk magnet yang digunakan adalah NdFeB tipe MQP-B+. Proses pencampuran dilakukan dengan menggunakan variasi komposisi $98 \% \mathrm{NdFeB}$ dan $2 \% \mathrm{ER}$, $96 \% \mathrm{NdFeB}$ dan $4 \% \mathrm{ER}, 92 \% \mathrm{NdFeB}$ dan $8 \%$ ER (dalam persen berat). Selanjutnya campuran tersebut dicetak dengan metode compress moulding menggunakan cetakan berdiameter $18 \mathrm{~mm}$. Gaya tekan yang digunakan sebesar 10 tonf. Hasil yang didapatkan dari proses pencetakan merupakan sampel berbentuk pellet yang kemudian dikeringkan di dalam mesin pengering pada suhu $80^{\circ} \mathrm{C}$ selama 4 jam. Pengujian yang dilakukan meliputi pengukuran bulk density, fluks magnetik dan histerisis loop menggunakan VSM. Hasil penelitian menunjukkan bahwa penambahan perekat epoksi resin menurunkan nilai densitas dan sifat magnet. Sampel komposit magnet NdFeB yang memiliki karakteristik yang baik adalah sampel dengan komposisi $2 \%$ dan $4 \%$ epoksi resin, dimana sampel ini memiliki densitas $=5,52 \mathrm{~g} / \mathrm{cm}^{3}$ dan $4,47 \mathrm{~g} / \mathrm{cm}^{3}$, fluks magnetik $=1064$ Gauss dan 1005 Gauss, serta memiliki remanensi $95 \mathrm{emu} / \mathrm{g}$ dan $85 \mathrm{emu} / \mathrm{g}$, nilai koersivitas $=400$ Oe dan 3500 Oe.
\end{abstract}

Kata kunci:. NdFeB, komposit magnet, epoksi resin, fluks magnetik, bulk densitas

Abstract: The NdFeB permanent magnet composites have been made with epoxy resin (ER) polymers. The magnetic powder used is $N d F e B$ type MQP-B +. The mixing process was carried out using variations in the composition of $98 \% N d F e B$ and $2 \% \mathrm{ER}, 96 \% \mathrm{NdFeB}$ and $4 \% \mathrm{ER}, 92 \% \mathrm{NdFeB}$ and $8 \% \mathrm{ER}$ (in weight percent). Furthermore, the mixture was formed by using compress molding method using a mold $18 \mathrm{~mm}$ in diameter. The compressive force used is 10 tonf. The results obtained from the compaction process are pellet shaped samples which are then dried in a drying machine at $80^{\circ} \mathrm{C}$ for 4 hours. Tests carried out include measurements of bulk density, magnetic flux and loop hysteresis using VSM. The results showed that the addition of epoxy resin adhesive decreased the value of density and magnetic properties. The NdFeB magnetic composite samples that have good characteristics are $2 \%$ and $4 \%$ epoxy resin compositions, where this sample has a density $=5.52 \mathrm{~g} / \mathrm{cm}^{3}$ and 4.47 $\mathrm{g} / \mathrm{cm}^{3}$, magnetic flux $=1064$ Gauss and 1005 Gauss, and has remanence of $95 \mathrm{emu} / \mathrm{g}$ and $85 \mathrm{emu} / \mathrm{g}$, coercivity value $=400$ Oe and 3500 Oe.

Keywords: NdFeB, magnet composite, epoxy resin, Flux magnetic, bulk density

\section{PENDAHULUAN}

Material magnet tergolong material yang strategis, karena material ini banyak dijumpai dalam kehidupan manusia sehari-hari. Baik di Industri maupun di rumah tangga akan dijumpai peralatan-peralatan atau mesin yang didalamnya terdapat komponen yang terbuat dari material magnet [1]. Sebagai contoh semua motor listrik baik di Industri maupun yang digunakan pada peralatan rumah tangga terdapat komponen magnet, peralatan kesehatan maupun sensor-sensor dan alat filter menggunakan komponen dari magnet [2]. Material magnet dibagi menjadi dua golongan yaitu magnet permanen yang disebut juga dengan nama hard magnet dan satu golongan lagi adalah magnet lunak atau dikenal denagn nama soft magnet [2,3]. Perbedaan secara teknis terletak pada gaya koersivitasnya, umumnya magnet permanen memilki kurva histeresis loop yang lebar dan memiliki nilai koersivitas $>500$ Oe. Sedangkan magnet lunak memiliki kurva histeresis loop yang sempit dan memiliki nilai koersivitas $<500$ Oe [3]. 
Jenis magnet permanen berdasarkan material pembentuknya yaitu berbasis $(\mathrm{Ba}, \mathrm{Sr}, \mathrm{Pb})$ - Ferrite, AlNiCo, SmCo, serta magnet logam tanah jarang yang dikenal berbasis NdFeB [4]. Dari berbagai magnet permanen tersebut bahwa magnet yang memiliki sifat magnet terbesar adalah magnet NdFeB. Saat ini magnet jenis ini banyak di produksi dari luar negeri dan banyak dipergunakan pada industri otomotif, komputer, divais pembangkit energi dan lain-lain. Di Indonesia sendiri kebutuhan magnet NdFeB masih diimport dari Cina dan Jepang, bahan baku di dalam negeri seperti logam tanah jarang dan pasir besi banyak terdapat di alam. Oleh karena itu saat perlu dilakukan riset tentang magnet $\mathrm{NdFeB}$ agar kedepan dapat muncul industri magnet $\mathrm{NdFeB}$ di Indonesia. Diharapkan kedepan import magnet permanen NdFeB dapat di kurangi.

Produk magnet permanen $\mathrm{NdFeB}$ ada dua macam yaitu sintered magnet $\mathrm{NdFeB}$ dan bonded magnet $\mathrm{NdFeB}$. Tentunya sintered magnet $\mathrm{NdFeB}$ di buat melalui proses powder metalurgi dan proses sintering pada suhu tinggi. Sedangkan bonded magnet NdFeB merupakan jenis magnet yang dibuat dari campuran partikel magnetik NdFeB dengan perekat dari bahan polimer, dan produk ini dikenal dengan nama komposit magnet permanen [5]. Polimer merupakan senyawa organik yang memiliki rantai ikatan yang panjang, contoh polimer yang sering digunakan pada pembuatan komposit magnet antara lain : Nylon, rubber, epoksi resin atau jenis-jenis plastik termosetting $[5,6]$.

Penelitian ini membahas tentang komposit magnet permanen NdFeB yang dibuat menggunakan polimer epoxy resin melalui metoda penekanan (cold pressing) serta karakterisasinya. Pembuatan dilakukan dengan memadukan polimer dengan partikel magnetik NdFeB. Penelitian ini bertujuan untuk mengetahui pengaruh variasi komposisi polimer terhadap sifat fisis dan sifat magnet.

\section{METODOLOGI}

Penelitian ini menggunakan bahan baky berupa serbuk magnet $\mathrm{NdFeB}$ jenis MQP B+ yang dibeli dari Cina dan menggunakan perekat polimer epoxy resin. Alat yang digunakan pada penelitian kali ini ialah neraca digital, alat-alat gelas, dies mould ,mesin hidraulik dan alat pengering. Alat ukur yang digunakan antara lain: gaussmeter, Vibrating Sample Magnetometer (VSM). Adapun tahapan pelaksanaan penelitian meliputi :

\section{Proses Pencampuran Bahan Baku}

Tahapan ini menimbang serbuk magnet dan cairan epoxy resin (ER) sesuai komposisi yaitu : 98\% NdFeB dan 2\%ER , 96\% NdFeB dan 4\% ER, 92\% NdFeB dan 8\% ER (dalam persen berat) dengan massa total sampel seberat 7 gram. Kedua bahan tersebut kemudian dicampurkan secara manual menggunalan beaker glass dan spatula sampai homogen.

\section{Pencetakan Sampel}

Pencetakan sampel uji berbentuk pelet berdiameter $18 \mathrm{~mm}$ dan tebal $6 \mathrm{~mm}$ menggunakan dies mould dan digunakan penekanan dengan mesin hidraulik dengan gaya sebesar 10 Tonf. Sampel pelet yang dihasilkan selanjutnya di keringkan pada suhu $80 \mathrm{oC}$ selama 4 jam menggunakan mesin pengering.

\section{Proses Magnetisasi}

Sampel pelet komposit $\mathrm{NdFeB}$ yang telah di keringkan dimagnetisasi menggunakan impulse mahnetizer dengan tegangan DC 1100 Volt.

\section{Karakterisasi}

Karakterisasi yang dilakukan dalam penelitian ini meliputi sifat fisis (densitas), sifat magnet (Fluks magnetik dan sifat kemagnetan bahan atau histerisis loop).

\section{HASIL DAN PEMBAHASAN}

Pengukuran bulk densitas dilakukan untuk mengetahui bagaimana sifat fisis dari sampel komposit $\mathrm{NdFeB}$ dengan variasi komposisi epoxy resin. Pengujian ini dilakukan untuk seluruh sampel dengan komposisi polimer yang berbeda-beda. Hasil pengujian densitas diperlihatkan pada Gambar 1. 
20 | Mulyadi dkk., Komposit Magnet Permanen Berbasis NdFeB -Epoxy....,

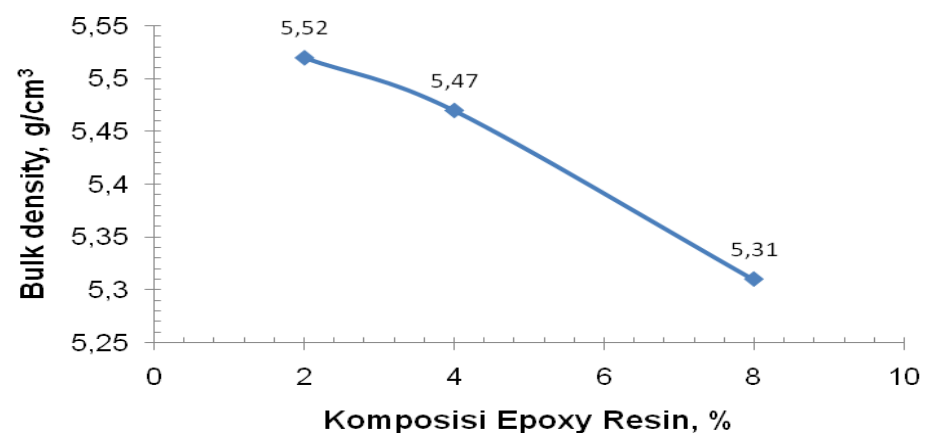

Gambar 1. Hubungan antara variasi komposisi epoksi resin dengan bulk density.

Dari grafik diatas dapat dilihat bahwa semakin banyak penambahan komposisi epoksi resin maka akan cenderung menurun nilai densitas nya. Hal ini dikarenakan adanya perbedaan densitas antara polimer epoksi resin dengan partikel magnetik, dimana densitas epoxy resin sekitar 1,5 g/ $\mathrm{cm}^{3}$ sedangkan densitas serbuk magnetik sekitar $6-7 \mathrm{~g} / \mathrm{cm}^{3}[6,7]$.

Semakin banyak epoksi resin maka kandungan partikel magnetik berkurang, sehingga densitas komposit akan menurun. Nilai densitas tertinggi pada sampel dengan $2 \%$ dan $4 \%$ epoxy resin dengan nilai masing-masing adalah : $5,52 \mathrm{~g} / \mathrm{cm}^{3}$ dan $5,47 \mathrm{~g} / \mathrm{cm}^{3}$.

Pengujian sifat magnet dilakukan untuk mengetahui sifat magnet (fluks magnetik) dari sampel komposit yang dibuat. Fluks magnetik merupakan besaran sifat magnet yang menyatakan besarnya kuat medan magnet pada permukaan sampel. Pengujian ini dilakukan untuk seluruh sampel dengan komposisi epoksi resin yang berbedabeda. Pengukuran fluks magnetik dilakukan dengan menggunakan alat gaussmeter. Hasil pengukuran fluks magnetik menggunakan gauss meter diperlihatkan pada Gambar 2.

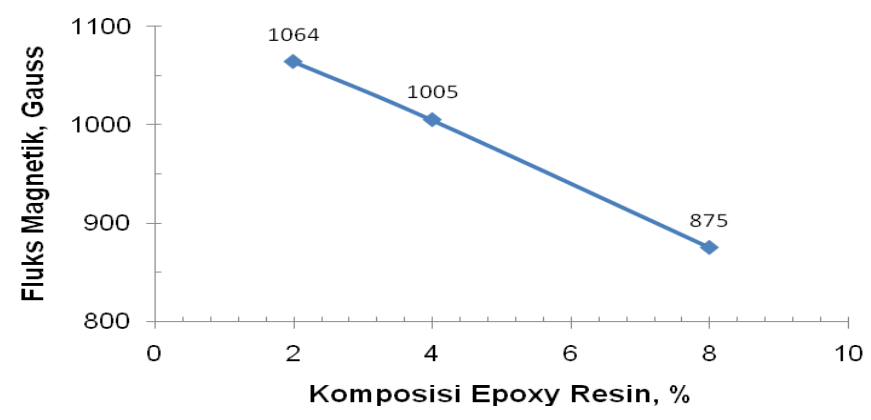

Gambar 2. Hubungan antara variasi komposisi dengan Fluks Magnetik.

Dari grafik diatas dapat dilihat bahwa semakin banyak penambahan epoksi resin maka akan cenderung menurun nilai fluks magnetik dari sampel komposit magent. Hal ini terjadi dikarenakan sifat dasar dari polimer itu sendiri adalah non-magnetik. Sehingga ketika komposisi epoksi resin semakin banyak menyebabkan nilai fluks magnetik dari sampel komposit akan mengecil. Pengujian sifat magnet dilakukan juga menggunakan Vibrating Sample Magnetometer (VSM) untuk sampel komposit dengan variasi penambahan epoksi resin $2 \%, 4 \%$ dan 8 \%. Kurva hasil pengukuran VSM diperlihatkan pada Gambar 3.

Pada Gambar 3 terlihat bahwa ketiga sampel komposit yang dibuat menunjukkan pola histerisis magnet permanen karena memiliki histerisis loop yang lebar dan ketiganya memiliki nilai koersivitas diatas 500 Oe. Hanya saja perbedaan dari ketiga sampel tersebut bahwa sampel denagn komposisi $2 \%$ dan $3 \%$ memiliki nilai remanesi paling besar dibandingkan dengan sampel dengan $8 \%$ epoksi resin, yaitu masing-masing memiliki remanensi $95 \mathrm{emu} / \mathrm{g}$ dan $85 \mathrm{emu} / \mathrm{g}$. Sedangkan nilai koersivitas nya adalah 4000 Oe dan 3800 Oe. Berdasarkan hasil kurva histeresis loop (Gambar 3) diperoleh parameter-parameter sifat magnet dari komposit magnet $\mathrm{NdFeB}$ yaitu diperoleh nilai remanensi $(\mathrm{mr})$ dan nilai koersivitas $(\mathrm{Hc})$ seperti diperlihatkan pada Tabel 1 


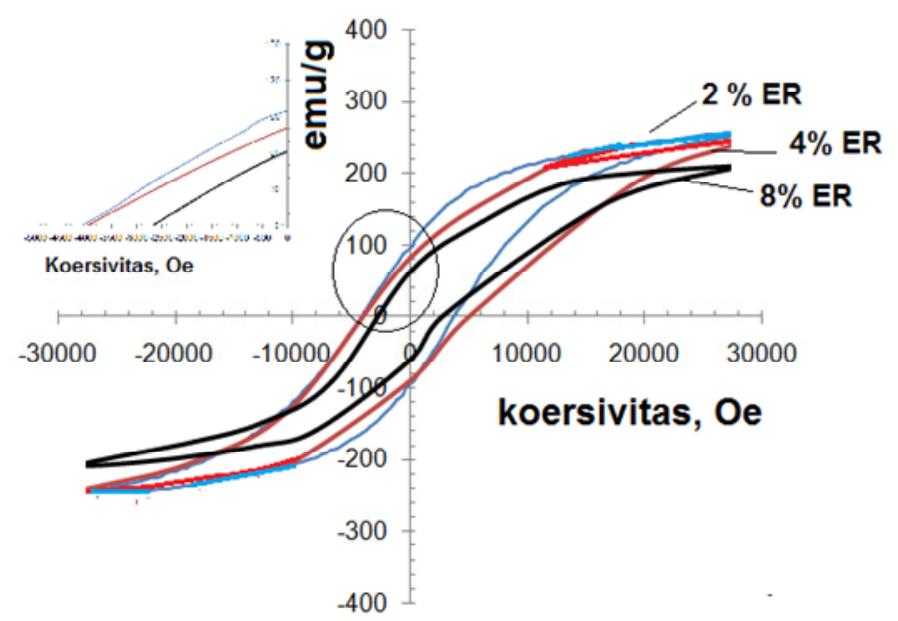

Gambar 3. Kurva histeresis komposit magnet $\mathrm{NdFeB}$ dengan variasi komposisi epoksi resin

Tabel 1. Karakteristik sifat magnet sampel komposit NdFeB

\begin{tabular}{ccc}
\hline $\begin{array}{c}\text { \% Epoksi } \\
\text { Resin }\end{array}$ & $\begin{array}{c}\text { Remanensi } \\
\text { emu/g }\end{array}$ & $\begin{array}{c}\text { Koersivitas } \\
\text { Oe }\end{array}$ \\
\hline 2 & 95 & 4000 \\
4 & 85 & 3800 \\
8 & 65 & 2750 \\
\hline
\end{tabular}

\section{KESIMPULAN}

Berdasarkan hasil penelitian yang dilakukan maka dapat di simpulkan sebagai berikut :Telah berhasil dibuat komposit magnet permanen $\mathrm{NdFeB}$ dengan komposisi epoksi resin $2 \%, 4 \%$ dan $8 \%$ berat.Komposisi epoksi resin memberikan pengaruh yang siqnifikan terhadap densitas, fluks magnetik dan kurva histerisis. Sampel komposit magnet $\mathrm{NdFeB}$ yang memiliki karakteristik yang baik adalah sampel dengan komposisi $2 \%$ dan $4 \%$ epoksi resin, dimana sampel ini memiliki densitas $=5,52 \mathrm{~g} / \mathrm{cm}^{3}$ dan $4,47 \mathrm{~g} / \mathrm{cm}^{3}$, fluks magnetik $=1064$ Gauss dan 1005 Gauss, serta memiliki remanensi $95 \mathrm{emu} / \mathrm{g}$ dan $85 \mathrm{emu} / \mathrm{g}$, nilai koersivitas $=400 \mathrm{Oe}$ dan $3500 \mathrm{Oe} .$.

\section{DAFTAR PUSTAKA}

[1] Sardjono P, Kurniawan C, Sebayang P dan Muljadi, Aplikasi Magnet Permanen di Indonesia: Data Pasar dan Pengembangan Material Magnet Seminar Nasional Ilmu Pengetahuan Teknik, 28 - 29 November 2012

[2] Malkinski L 2012 Advanced Magnetic Materials, Published by InTech Janeza Trdine 9, 51000 Rijeka, Croatia

[3] Kirchmayr H R 1996 J. Phys. D: Appl. Phys. 292763

[4] Brown D, Ma B -M dan Chen Z 2002 Journal of Magnetism and Magnetic Materials 248432

[5] Sojer D, Kull I, Kobe S, Kova J dan McGuiness P J 2013 MTAEC9 47(2) 223

[6] Stajčić A P, Stajić-Trošić J T, Grujić A S, Stijepović M Z, Lazić N L, Žák T and Aleksić R R 2012 Hem. Ind. 66(3) 301

[7] Drak M and Dobrzański L A 2007 Journal of Achievements in Materials and Manufacturing Engineering 20(1-2) 